\title{
Multilevel Thresholding of Brain Tumor MRI Images: Patch-Levy Bees Algorithm versus Harmony Search Algorithm
}

Preliminary Communication

\author{
Farah Aqilah Bohani \\ The National University of Malaysia, \\ Faculty Information Science and \\ Technology, Centre for Artificial \\ Intelligence Technology, \\ 43650 Bangi, Selangor, Malaysia \\ The Energy University \\ Institute of Energy Infrastructure, \\ 43000, Kajang, Selangor, Malaysia. \\ farahbohani@yahoo.com
}

\section{Ashwaq Qasem}

The National University of Malaysia Faculty of Information Science and Technology, Centre for Artificial Intelligence and Technology 43650 Bangi, Selangor, Malaysia eng.ashwaq@gmail.com

\section{Siti Norul Huda Sheikh Abdullah}

The National University of Malaysia Faculty of Information Science and Technology, Center for Cyber Security 43650 Bangi, Selangor, Malaysia snhsabdullah@ukm.edu.my

\author{
Khairuddin Omar \\ The National University of Malaysia \\ Faculty of Information Science and \\ Technology, Centre for Artificial \\ Intelligence and Technology \\ 43650 Bangi, Selangor, Malaysia \\ ko@ukm.edu.my
}

\section{Shahnorbanun Sahran}

The National University of Malaysia Faculty of Information Science and Technology, Centre for Artificial Intelligence and Technology 43650 Bangi, Selangor, Malaysia shahnorbanun@ukm.edu.my

\section{Rizuana lqbal Hussain}

The National University of Malaysia Tuanku Muhriz Hospital Counselor, Department of Radiology 56000, Cheras, Kuala Lumpur, Malaysia rizuana@ppukm.ukm.my

\author{
Syaza Sharis \\ The National University of Malaysia \\ Tuanku Muhriz Hospital Counselor, \\ Department of Radiology \\ 56000, Cheras, Kuala Lumpur, \\ Malaysia \\ syazasharis@yahoo.com
}

\begin{abstract}
Image segmentation of brain magnetic resonance imaging (MRI) plays a crucial role among radiologists in terms of diagnosing brain disease. Parts of the brain such as white matter, gray matter and cerebrospinal fluids (CFS), have to be clearly determined by the radiologist during the process of brain abnormalities detection. Manual segmentation is grueling and may be prone to error, which can in turn affect the result of the diagnosis. Nature inspired metaheuristic algorithms such as Harmony Search (HS), which was successfully applied in multilevel thresholding for brain tumor segmentation instead of the Patch-Levy Bees algorithm (PLBA). Even though the PLBA is one powerful multilevel thresholding, it has not been applied to brain tumor segmentation. This paper focuses on a comparative study of the PLBA and HS for brain tumor segmentation. The test dataset consisting of nine images was collected from the Tuanku Muhriz UKM Hospital (HCTM). As for the result, it shows that the PLBA has significantly outperformed HS. The performance of both algorithms is evaluated in terms of solution quality and stability.
\end{abstract}

Keywords - Brain MRI, HS, multilevel thresholding, Otsu, PLBA, segmentation.

\section{INTRODUCTION}

Cancer is the second mortality causing factor in the world with 8.8 million cases reported as of 2015 [1]. In Malaysia, cancer is the third highest contributor to mortality [2]. Categorically speaking, Malays have the highest survival rate among those affected by brain and nervous system cancers, which amounts to 43\%, as reported by the Malaysian Study on Cancer Survival (MySCan), 2018. This has become the second highest rate in terms of survivors, with ovarian cancer $(54.8 \%)$ 
and stomach cancer $(27.6 \%)$ being is the first and the third, respectively [1]. Indians and Chinese have the highest survival percentage in other types of cancer [1]. It can be concluded that Malays have a higher risk of developing brain cancer in Malaysia.

Brain tumor or brain cancer is a cluster of abnormal cells in the human brain [3]. There are two types of tumors, namely malignant (cancerous) and benign (non-cancerous) [3]. Medical imaging is an important medium for radiologists to accurately diagnose brain disease such as cancer. High resolution MRI of the brain is needed for better brain tumor detection.

The advantage of MRI is that it is the least risky method for constructing data with spatial resolution in high scale and non-invasive modality compared to other techniques of diagnostic imaging [4]. There are several methods that have been applied successfully in MR image segmentation.

Manual segmentation of MRI images is arduous, expensive and time consuming. Any mistake is susceptible due to blurriness on tissues boundaries, low tissue contrast and poor hand-eye coordination. Consequently, discrepancies are common among radiologists determining a variety of structures. Therefore, a plethora research studies were introduced to increase the accuracy of brain tissues segmentation upon brain disease diagnosis.

Effective brain MRI segmentation can improve a classification of brain diseases with better precision. Joliot et al. [5] proposed a technique of three-dimensional automatic segmentation that separates gray level thresholding of gray matter and white matter. In fact, brain MRI images occasionally have some noise component as a result of patient movement during brain scanning. Raquel et al. [6] introduced a hybrid model for multispectral brain MRI segmentation based on a radial basic network. This method falls short of solving the brain MRI images with noise. To overcome this problem, a clustering method is put forth.

In a number of pixel-based approaches, the clustering method has the most prominent application in terms of image segmentation [7]. In the last decade, clustering-based approaches garnered significant interest in the domain of medical imaging. The fuzzy cmeans (FCM) clustering algorithm was introduced by Bezdek [8] to minimize an objective function which is known as fuzzy membership and a set of cluster centroids. However, FCM still blunders in separating the pixel since it contains noisy pixels.

Histogram-based thresholding is a very popular tool in image segmentation. Bi-level thresholding is also known as the simplest problem compared to multi-level thresholding. Bi-level thresholding segments the image into two groups. If the image consisting of a gray-pixel level is higher than the threshold, it is defined as one group. Otherwise, it is included as another group. In the case of multilevel thresholding, it is more challenging to define a group of pixels when more details of segmentation are produced. Determining distinct valleys in a multilevel histogram is no easy task. Hence, the problem of multilevel thresholding has become the point of interest among researchers.

Otsu's method [9], which is also known as a nonparametric approach, selects optimal thresholds by maximizing the between-class variance of gray levels. Gray levels of the image are normally distributed [10]. This method is easy and powerful in bi-level thresholding [10]. Otsu's method can possibly be applied in multilevel thresholding. However, it is significantly formidable to determine optimal thresholds due to exponential growth in computation time. Owing to that, numerous methods for solving the multilevel thresholding problem have been proposed [11].

Multilevel thresholding-based metaheuristics is proposed by the researchers to increase search speed as it has been attested to yield the best result in (optimal) thresholds. Brain MRI segmentation focuses on the normal brain by using bacterial foraging optimization (BFO) [12], a genetic algorithm (GA) [13], and adaptive bacterial foraging optimization (ABF) [14], which have been successfully implemented.

Brain tumor MRI images encompass various artifacts such as cyst, solid and edema. Multilevel thresholding of brain tumor MRI images segmentation is also successfully applied based on metaheuristic methods such as harmony search (HS) [15]. The advantage of the Patch-Levy Bees Algorithm (PLBA) is that it is more realistic and it is attained by speeding up the search process to find an optimal threshold based on multilevel thresholding for image segmentation [16]. The PLBA has never been applied in brain MRI segmentation. Owing to that, compared to HS, the PLBA is deemed interesting for the application in brain tumor MRI images, by using the recent methods to provide better brain tumor image segmentation.

\section{IMAGE THRESHOLDING}

Image thresholding is one of the types of image segmentation techniques. It segments an image into different intensity levels of color or gray images. Image segmentation through image thresholding is the most convenient and effortless method effortless. Threshold values are the intensity values selected from the color or gray intensities of the image. Based on selection of these threshold values, an image is segmented into different regions.

\subsection{GLOBAL THRESHOLDING}

Global thresholding has one threshold to segment into two partitions [17]. It operates in such a way that if any gray value of images is higher than the threshold value, it will join into one group; otherwise, it will join into the other group. 
Even though global thresholding is so easy to implement, it only considers segmentation of the image into two partitions. It may suffer from the loss of sharp pixels to classify in the image whose color intensities are more similar to other uniquely classified pixels. The global thresholding method is also known as a bi-level thresholding method.

\subsection{MULTILEVEL THRESHOLDING}

Multilevel thresholding considers segmentation of more than one threshold value into several groups [17]. The number of segmented images is one more than the number of threshold values chosen. It can be concluded that if three threshold values are selected, it will produce four groups of regions for the segmented image. Generally, some of the sharp pixels that went through global thresholding may be lost or missing after performing segmentation separately. For the purpose of solving the shortcomings of global thresholding, multilevel thresholds are selected.

Gray images have $L$ levels of gray in the range $(0,1,2$, ... , L-1 1). Let $h(1), h(2), \ldots, h(L-1)$, be the observed graylevel frequency. The probability of occurrence of the gray level i can be defined as in (1):

$$
P_{i}=\frac{h(i)}{N} \text { for }(0 \leq i \leq L-1) \text {, }
$$

where $h(\mathrm{i})$ is the number of pixels corresponding to the gray level $i$ and $\mathrm{N}$ is the total number of pixel in the image, which is equal to $\sum_{i=0}^{L-1} h(i)$

\section{BRIEF DESCRIPTION OF THE COMPARED ALGORITHMS}

\subsection{HARMONY SEARCH}

Harmony search (HS) was introduced by Geem in 2001 [18], based upon the idea that it can imitate the behavior that a musician needs, a well-balanced harmony. The advantage of HS is that it has a simple model and good performance in the global search domain. Furthermore, HS has been applied in numerous real-world optimization problems [19-21]. HS steps are shown in Algorithm 1.

The first step of HS is to initialize the harmony memory size HMS, harmony memory consideration rate $H M C R$, maximum dimension $D$, the pitch adjusting rate $P A R$ and the bandwidth $B W$.

Then, the second step is to initialize harmony memory $x$, as in (2):

$$
x_{i, j}=x_{j, L}+\operatorname{rand} .\left(x_{j, U}-x_{j, L}\right),
$$

where $x_{j, L}$ and $x_{j, U}$ are lower bounds for a decision variable. In step 3, check the memory consideration of HS. If $R_{1}$ is smaller than HMCR, execute as in (3):

$$
x_{n e w, j=} x_{r, j}(r \in 1,2,3, \ldots H M S),
$$

where $x_{r, j}$ is the index random of the harmony memory for one dimension, $r \in 1,2,3, \ldots H M S$ and $j \in\{1,2,3, \ldots D\}$, while $D$ is the maximum number of dimensions.

After that, check the pitch adjustment condition; if $R_{2}$ is smaller than $P A R$ and $R_{3}$ is smaller than 0.5 , execute as in (4):

$$
x_{n e w, j}=x_{n e w, j}+\varphi \times B W,
$$

where $\varphi$ is a random number uniformly distributed in the range $[-1,1]$ and $B W$ is a constant value. If $R_{3}$ is larger than 0.5 , execute as in (5):

$$
x_{n e w, j}=x_{n e w, j}-\varphi \times B W .
$$

If $R_{1}$ is larger than HMCR, follow (6):

$$
x_{n e w, j}=x_{j, L}+\operatorname{rand} .\left(x_{j, U}-x_{j, L}\right),
$$

where rand is a random number uniformly distributed in the range $[0,1]$.

In step 4 , if $f\left(x_{\text {new }}\right)$, which is an objective function of the new harmony memory $x_{\text {new' }}$ is smaller than $f\left(x_{\text {worst }}\right)$, which is an objective function of the worst harmony memory $x_{\text {worst }}$ execute as in (7):

$$
x_{\text {worst }}=x_{\text {new }} .
$$

\section{Algorithm 1: HS}

Input: Harmony memory size HMS, harmony memory consideration rate, $H M C R$ maximum dimension $D$, maximum generation $G$, pitch adjusting rate, $P A R$ and bandwidth, BW

Output: worst harmony, $x_{\text {worst }}$ function objective of worst harmony $f\left(x_{\text {worst }}\right)$

Step 1: Initialize HMS, HMCR, PAR, D, G, and PAR.

Step 2: Initialize harmony memory HM as below:

$$
\begin{aligned}
& \text { For } \mathrm{i}=1 \text { to } H M S \text { do } \\
& \text { For } \mathrm{j}=1 \text { to } D \\
& \text { Execute as in (2). } \\
& \text { End For }
\end{aligned}
$$

Calculate $f\left(x_{i}\right)$

End For

Step 3: Improvise $\mathrm{g}=0$, while the stopping criterion is inadequate $(\mathrm{g}<\mathrm{G})$ do

$$
\begin{aligned}
& \text { For } \mathrm{j}=1 \text { to } D \text { do } \\
& \text { If } R_{1} \leq H M C R \\
& \% \text { memory consideration } \\
& \text { Execute as in (3). } \\
& \% \text { pitch adjustment } \\
& \text { If } R_{2} \leq P A R \text { then }
\end{aligned}
$$




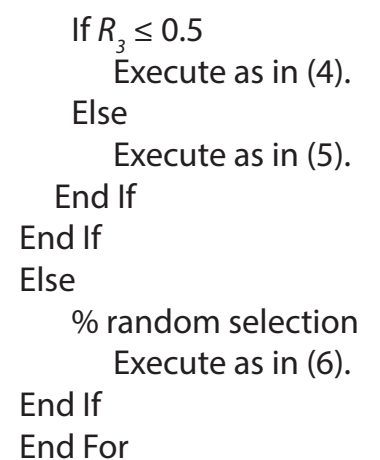

Step 4: Update the worst harmony.

Select the worst harmony vector $x_{\text {worst }}$ in the current harmony memory and calculate $f\left(x_{\text {new }}\right)$ and $f\left(x_{\text {worst }}\right)$

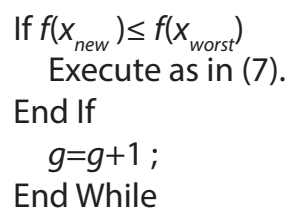

Step 5: Algorithm stops when the best solution is obtained.

\subsection{PATCH-LEVY BEES ALGORITHM (PLBA)}

The PLBA algorithm was proposed by Wasim et al. in 2016 [16]. During initialization, local search and global search of the PLBA, a patch concept and the Levy distribution were modeled. Using patch with the PLBA helps us distribute solutions in the search space, while the Levy distribution is used to get the benefit of its concept and step size. Levy distribution step size usually comprises several short steps followed by occasional longer jumps. Short steps make the exploitation of the most promising area on which the majority of the population is focused. However, a rarely long jump keeps exploring the search space by part of the population. Generally, patch and levy flights make the PLBA track more than one pick in terms of the maximization problem. Using a suitable step size of levy flights in initialization and global search, the PLBA maintained the diversity of the solution because of the rarely long jump.

The PLBA is attested to select accurate thresholds for image segmentation [16]. In comparison to Kapur's objective functions, Otsu's show a better segmentation result.

The PLBA solution represents a combination of $r$ thresholds. Hence, the bee solution can be represented as in (8).

$$
\text { bee }=\left(t_{1}, t_{2}, \ldots, t_{r}\right)^{T},
$$

where $t_{1} \in\left[0, L_{1}\right]$ and $t_{i}<t_{i+1}$ for all $t \in[1, r]$.

The PLBA-based algorithm steps are shown in Algorithm 2. Generally, initializing the threshold values is done with levy step $\gamma=\gamma_{1}$ as in (9), while in global search the levy step $\gamma=\gamma_{3}$. Local search is performed as in (10).

$$
\begin{aligned}
& t_{i}=c_{j}+(2 r-1) \times \operatorname{Levy}(\gamma) \\
& i=1,2, \ldots, n ; j=1,2, \ldots, P
\end{aligned}
$$

where $c_{j}$ is the center of the $j^{\text {th }}$ patch, $r \in$ uniform $(0,1)$, and gives the direction to the flight.

$$
\begin{gathered}
t_{i}=t_{\text {bestcur }}+(2 r-1) \times \operatorname{Levy}\left(\gamma_{2}\right), \\
i=1,2, \ldots, \text { nep (or nsp). }
\end{gathered}
$$

\subsection{OTSU'S CRITERION}

Otsu's thresholding is a well-known method in image segmentation. It is used to choose optimal thresholding by maximizing the variance between different classes and minimizing it within the same class.

Let $h$ be the gray-level histogram of an image with $L$ gray levels and $N$ pixels. So $h(i)$ is the number of gray levels $i, i \in[0, L]$ in the image. Then, the probability of gray level $i$ in the image can be calculated as in (11).

\section{Algorithm 2: PLBA}

Input: Number of thresholds ( $r$ ), number of iterations $(s)$, number of scout bees $(n)$, number of selected sites $(m)$, number of elite sites $(e)$, Number of recruited bees for each site of the e sites, (nsp), number of bees recruited for every site of the remaining, (m-e) sites, (nsp), Step size of Levy flights $\left(\gamma_{1}\right)$, Step size of Levy flights $\left(\gamma_{1}\right)$, and step size of Levy flights $\left(\gamma_{3}\right)$

Output: Optimal threshold values $\left(t_{1}, t_{2}, \ldots, t_{r}\right)$

Step 1: Initialize each scout bees as in (8); with a combination of threshold values defined as in (9)

Step 2: Evaluate the fitness of each combination of thresholds as in (18) for the PLBA-Otsu algorithm.

Step 3: Repeat for s or until a given stopping criterion is met

3.1: Select the best $\mathrm{m}$; where $\mathrm{m}<\mathrm{n}$; combinations of thresholds from the population

3.2: Select the best e ; where $\mathrm{e}<\mathrm{m}$; combinations of thresholds from the population

3.3: Start local search around the best $m$ combinations by generating more combinations of thresholds (nep) around e combinations and (nsp) threshold combinations generated around the remaining $m$-e combinations. Each combination of thresholds $\left(t_{i}\right)$ is represented as in (8) and generated as in (10),

where $t_{\text {bestcur }}$ is the current best combination of thresholds in the neighborhood,

3.4: Start global search by redistributing the remaining $n-m$ bees by creating a new solution represented as in (8) and (9)

3.5: Evaluate the fitness of each combination of the $n-m$ combinations as in (18).

3.6: Choose the best threshold combination of local and global search

Step 4: A combination of thresholds with the best fitness value is chosen to represent the optimal thresholds. 


$$
P_{i}=\frac{h(i)}{N}, P_{i} \geq 0, \sum_{i=1}^{L-1} P_{i}=1
$$

Otsu [9] introduced three discriminant criteria based on discriminate analysis to measure separation as in (12).

$$
\lambda=\frac{\sigma_{B}^{2}}{\sigma_{W}^{2}}, k=\frac{\sigma_{T}^{2}}{\sigma_{W}^{2}}, n=\frac{\sigma_{B}^{2}}{\sigma_{T}^{2}},
$$

where $\sigma_{B}^{2}$ is the variance between classes, $\sigma_{W}^{2}$ is the variance within class and $\sigma_{T}^{2}$ is the total variance of gray levels.

In bi-level thresholding, Otsu divided the image into two classes, i.e. the first class $C_{1}$ with pixels in the range $[0, t-1]$, and the second class $C_{2}$ with pixels in the range $[\mathrm{t}, L-1]$ by threshold $t$. The between class variance is calculated as in (13).

$$
\begin{aligned}
\sigma_{B}^{2}(t)=w(0, t) & (\mu(0, t)-\mu(0, L))^{2} \\
& +w(t, L)(\mu(t, L)-\mu(0, L))^{2},
\end{aligned}
$$

where $w(0, t)=\sum_{i=0}^{t-1} p_{i}$ is the weight of the first class $C_{1}, \mathrm{w}(t, L)=\sum_{i=t}^{L-1} p_{i}$ is the weight of the second class $C_{2}$ and $w(0, t)+w(t, L)=1$.

The mean of the first and second classes is given as in (14) and (15).

$$
\begin{aligned}
& \mu(0, t)=\sum_{i=0}^{t-1} \frac{i p_{i}}{w(0, t)}, \\
& \mu(t, L)=\sum_{i=t}^{L-1} \frac{i p_{i}}{w(t, L)}
\end{aligned}
$$

The total mean level of the original image is defined as in (16).

$$
\mu(0, L)=w(0, t) \mu(0, t)+w(t, L) \mu(t, L) .
$$

Otsu's thresholding method selects the optimal thresholds $t^{*}$ by maximizing the between class variance of (12) as follows (17):

$$
t^{*}=\operatorname{argmax}\left\{\sigma_{B}^{2}\right\}
$$

Assuming $r$ thresholds were supposed to be chosen, two dummy thresholds $t_{0}=0$ and $t_{r}+1=0$ are used for computational convenience, and the objective function becomes as in (18):

$$
\sigma_{B}^{2}\left(t_{1}, t_{2}, \ldots, t_{r}\right)=\sum_{i=0}^{c} w\left(t_{1}, t_{i+1}\right)\left(\mu\left(t_{1}, t_{i+1}\right)\right.
$$

\section{EXPERIMENTAL SETUP}

\subsection{TEST IMAGE}

The MRI data for this research collected from the Hospital Counselor Tunku Muhriz (HCTM) with a sample T2 weighted of 9 axial plane brain images for 2 patients

\begin{tabular}{|c|c|c|c|}
\hline $\begin{array}{c}\text { Test } \\
\text { Image }\end{array}$ & Brain Tumor Type & $\begin{array}{l}\text { Number of } \\
\text { Patient Data }\end{array}$ & $\begin{array}{c}\text { Spatial } \\
\text { Resolution }\end{array}$ \\
\hline Slice 9 & \multirow{8}{*}{$\begin{array}{l}\text { Intraventricular } \\
\text { Tumor with } \\
\text { Epidermoid cyst }\end{array}$} & Patient A & $1494 \times 1780$ \\
\hline Slice 162 & & Patient A & $1170 \times 1344$ \\
\hline Slice 164 & & Patient A & $1170 \times 1344$ \\
\hline Slice 165 & & Patient A & $1170 \times 1344$ \\
\hline Slice 166 & & Patient A & $1170 \times 1344$ \\
\hline Slice 167 & & Patient A & $1170 \times 1344$ \\
\hline Slice 168 & & Patient A & $1170 \times 1344$ \\
\hline Slice 169 & & Patient A & $1170 \times 1344$ \\
\hline Slice 38 & $\begin{array}{c}\text { Small Falx } \\
\text { Meningioma with } \\
\text { Arachnoid Cyst }\end{array}$ & Patient B & $1024 \times 1024$ \\
\hline
\end{tabular}
represented as Patient $A$ and Patient $B$ are shown in Table 1. Patient $A$ is a 40-year old Malay male and Patient $B$ is a 48-year old Malay female. T2-weighted images in JPEG format show water brighter and fat darker. The details of each image are shown in Table 1 and the images with their histograms are shown in Fig. 1.

Table 1. Details of brain MRI images collected from HCTM

\subsection{PERFORMANCE EVALUATION}

\section{A. Uniformity}

Uniformity measured was employed to compare optimization technique performance [22]. The misclassification error is calculated by (19):

$$
U=1-2 * c * \frac{\sum_{j=0}^{c} \sum_{i \in R_{j}}\left(f_{i}-\mu_{j}\right)^{2}}{N *\left(f_{\max }-f_{\min }\right)^{2}}
$$

where $c$ is the number of thresholds used to segment the image. $R_{j}$ is the $j$ th segmented region and $f_{i}$ is the intensity level of pixels for the segmented region. $\mu_{j}$ is the mean of the $j$ th segmented image and $N$ is a total of pixels in the image. Maximum and minimum intensity of an image are represented as $f_{\text {max }}-f_{\text {min }}$, respectively. Generally, misclassification errors may lie between 0 and 1 .

The performance of the algorithm is better when the misclassification error is high.

Thus, the uniformity is an indication of better image quality when $U=1$, and of worse image quality when $U=0$. 


\section{B. Stability}

If the performance in each run is not unique, it is evaluated by more than one run. Each run obtained different initial values. The robustness of the algorithm is based on the acceptance of its outcome. Therefore, the algorithm was run for 50 times.

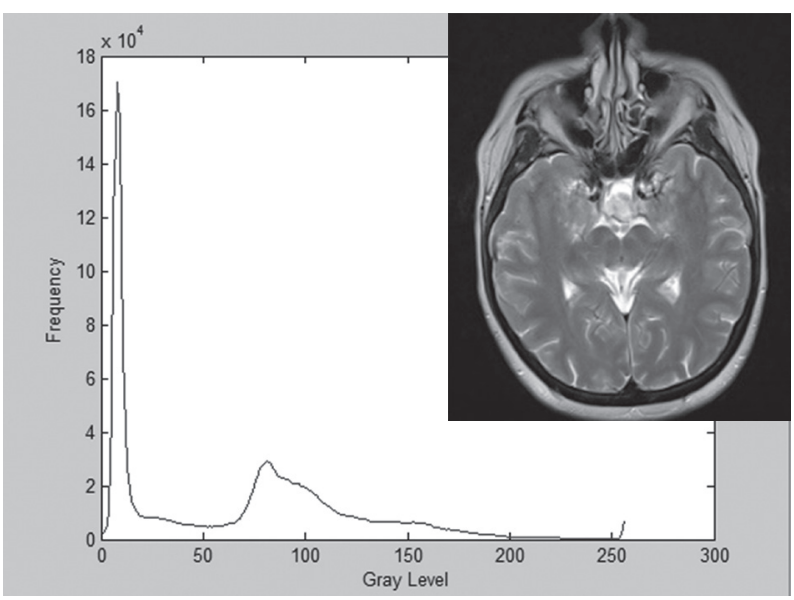

(a)

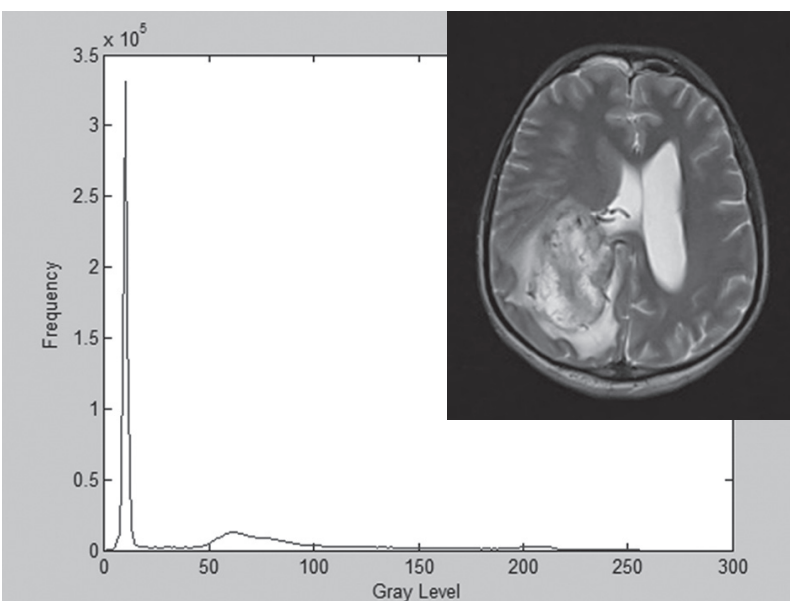

(b)

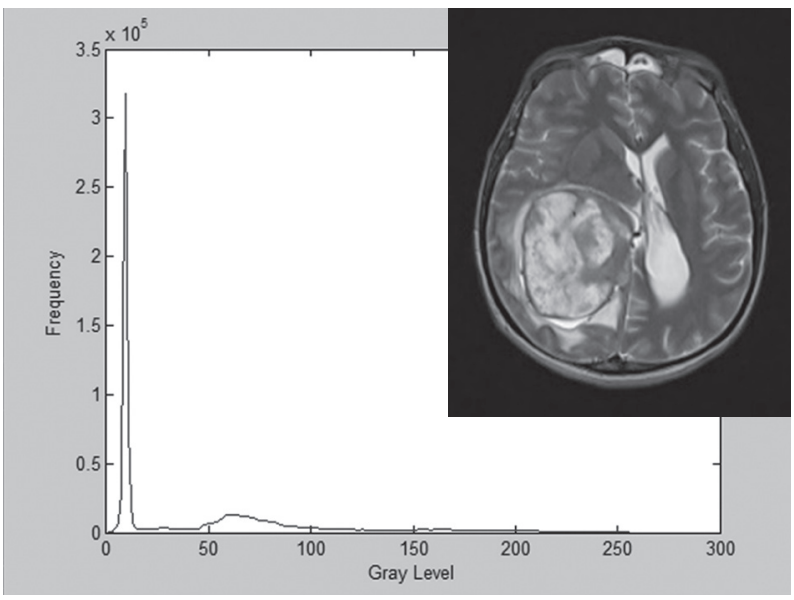

(c)
The stability of the algorithm evaluated was based on the average of the mean and standard deviation for all runs. If each run hardly varies from one to another, the algorithm was considered to be stable. The mean and standard deviation are demonstrated as in (20) and (21).

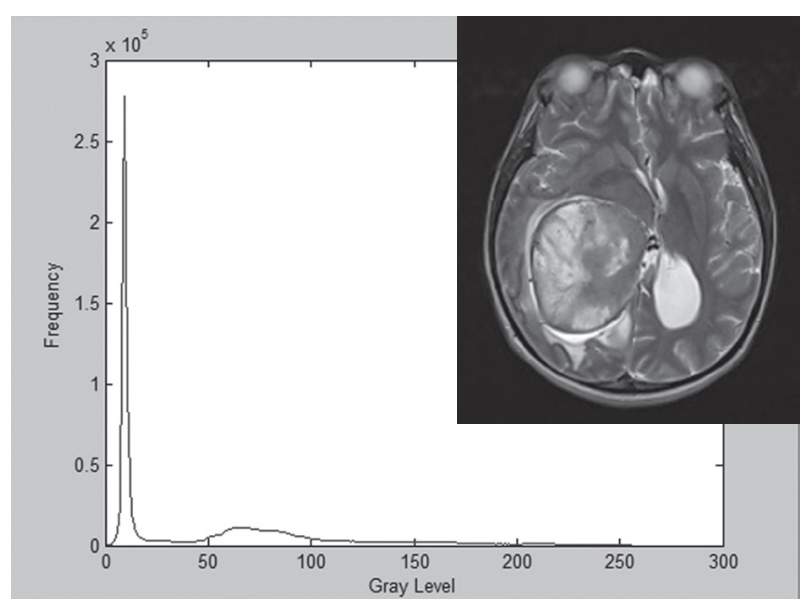

(d)

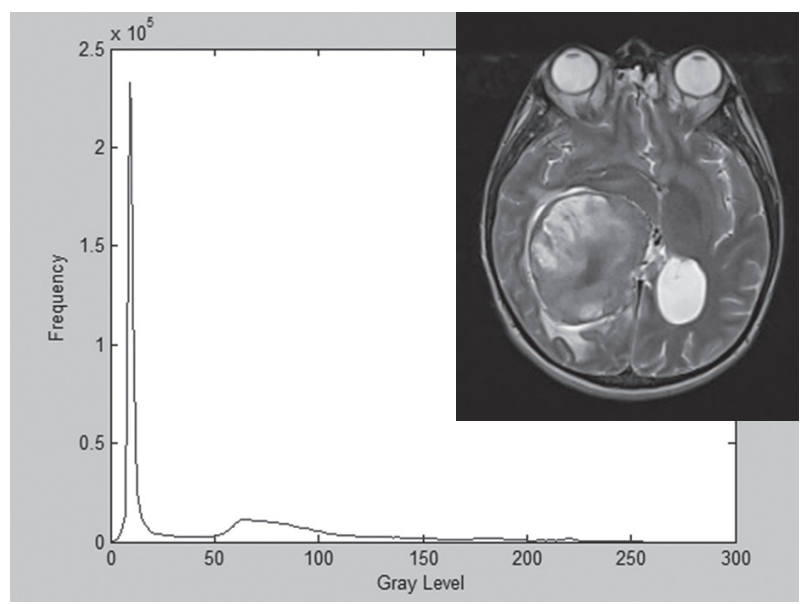

(e)

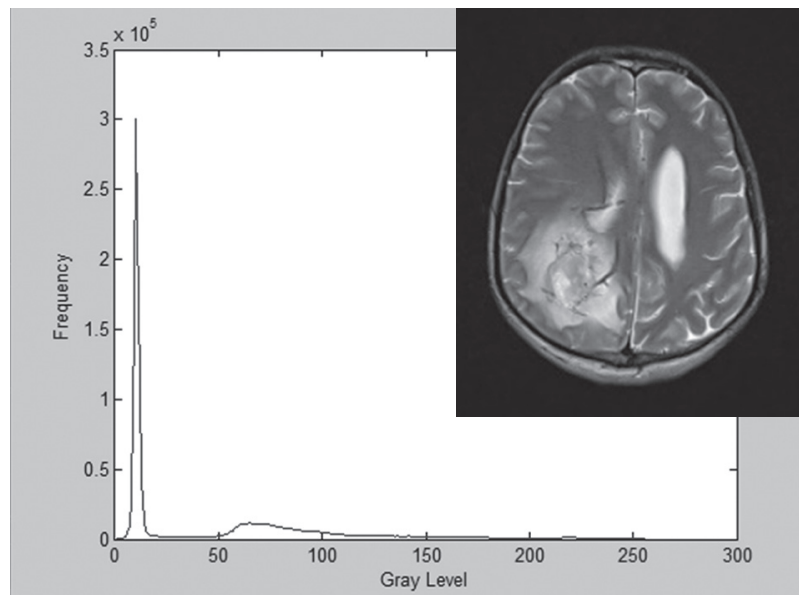

(f) 


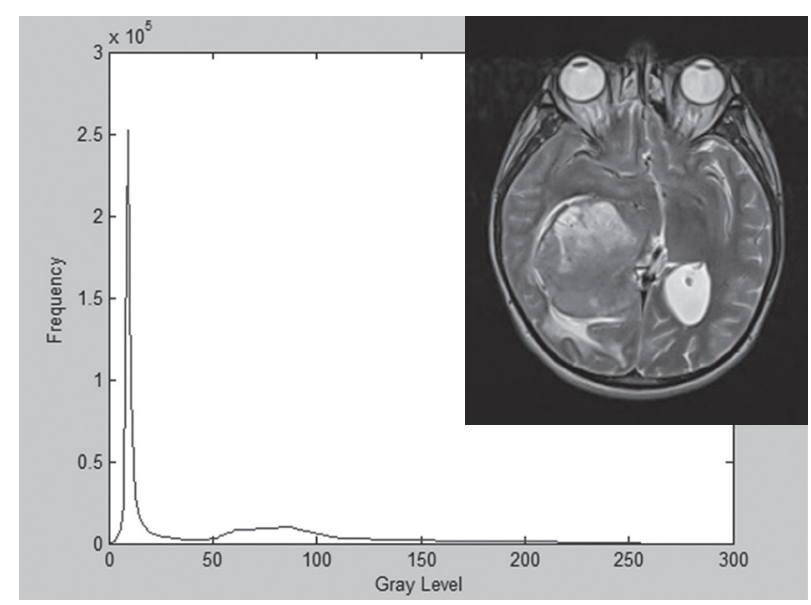

(g)

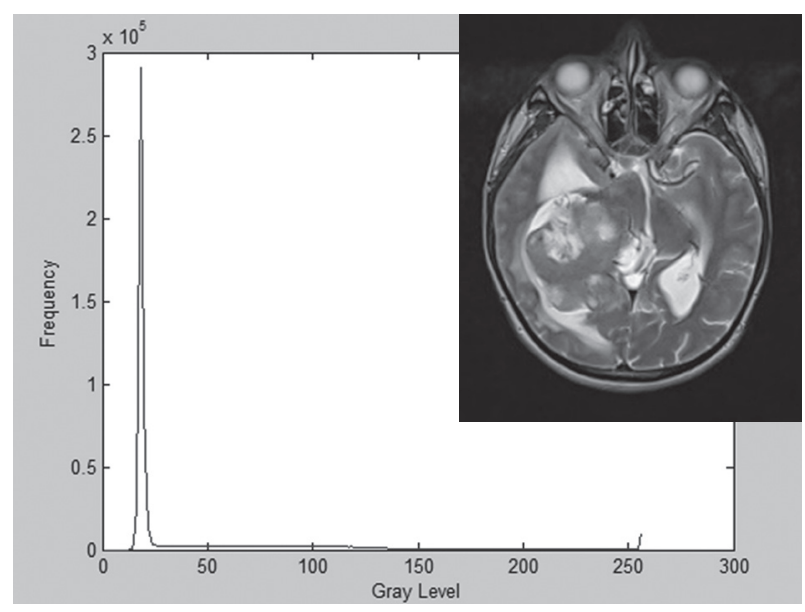

(h)

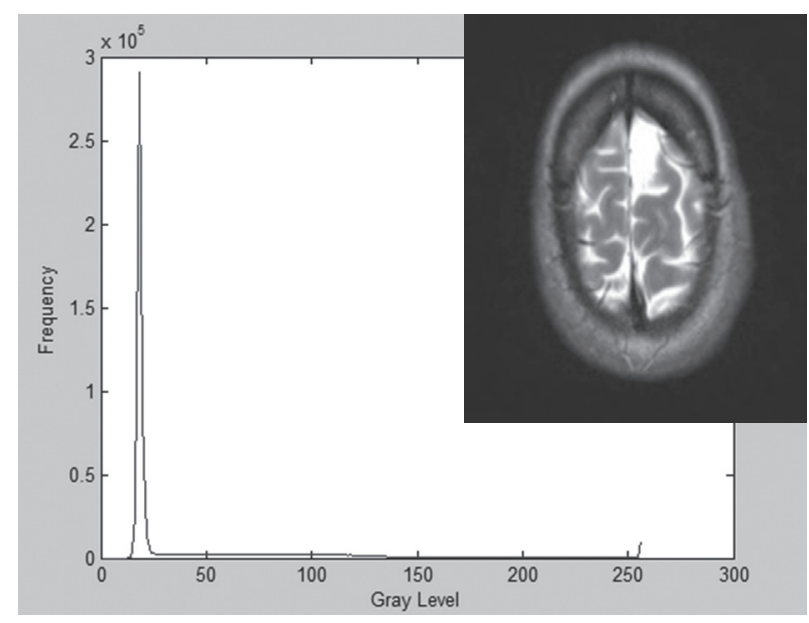

(i)

Fig. 1. Original image and the grayscale histogram of an image

$$
\begin{gathered}
\text { mean }(\sigma)=\frac{1}{N} \sum_{j}^{N} \mu_{j}, \\
\text { standard deviation }=\sum_{j=1}^{N}\left(\mu_{j-} \sigma\right)^{2},
\end{gathered}
$$

where $\mu_{\mathrm{i}}$ is the objective function value or the fitness value at the $j$ th run and $N$ is the number of run.

\section{Structural Similarity Index (SSIM)}

SSIM measures the similarity between the original image and the thresholded image, and it is expressed as follows:

$$
\begin{gathered}
S S I M=\frac{\left(2 \mu_{i} \mu_{i}+C 1\right)\left(2 \sigma_{i i}+C 2\right)}{\left(\mu_{i}{ }^{2}+\mu_{i}{ }^{2}-C 1\right)\left(\sigma_{I}^{2}+\sigma_{I}^{2}-C 2\right)}, \\
\sigma_{i i}=\frac{1}{N-1} \sum_{i=1}^{N}\left(I_{i}-\mu_{I}\right)\left(\tilde{I}_{i}-\mu_{\tilde{I}}\right),
\end{gathered}
$$

where $\mu_{1}$ and $\mu_{\tau}$ are the mean values of the original image $I$ and the reconstructed image $\tilde{l}$, and $\sigma_{\tilde{l}}$ is the standard deviation of the original image $I$ and the reconstructed image $\tilde{I}, \sigma_{\tilde{I}}$ is the cross-correlation and C1 and $\mathrm{C} 2$ are constants equal to 0.065 . The SSIM ranges between -and +1 and the SSIM value is equal to one. This shows that the original image and the reconstructed image (a threshold image) are similar. It is presumed that the algorithm can produce acceptable $p$ performance if the SSIM value is close to 1 .

\section{Peak Signal-to-Noise Ratio (PSNR)}

The PSNR, which is quantified in decibels $(\mathrm{dB})$, shows a dissimilarity between an input image and a threshold image. A higher value of the PSNR requires better quality of the threshold image. RMSE and the PSNR values are calculated as follows:

$$
\begin{gathered}
R M S E=\sqrt{\frac{1}{M N} \sum_{I}^{M} \sum_{J}^{N}[\mathrm{f}(\mathrm{I}, \mathrm{J}) \tilde{\mathrm{f}}(\mathrm{I}, \mathrm{J})]^{2}}, \\
P S N R=20 \log _{10}\left(\frac{255}{R M S E}\right),
\end{gathered}
$$

where $M \times N$ is the size of an image, while / and $J$ represent the pixel values of the original and decompressed images, respectively. In this experiment, researchers have taken $M \times N$ to be a square image. $f(I, j)$ is an original image, whereas $\tilde{f}(1, j)$ is a reconstructed image.

\subsection{PARAMETER SETTINGS}

For PLBA-Otsu and HS-Otsu tests presented in this paper, the default parameters of all methods are listed in tables 2 and 3, respectively. The PLBA-Otsu parameter values were suggested by Wasim et al. in 2016 [16]. The Levy step size in local search $\left(r_{1}\right)$ was set to a small value to support the exploitation capability of good regions, while the Levy step size in global search and initialization $\left(r_{2}\right.$ and $\left.r_{3}\right)$ was set to large values to maintain the diversity of the population [16]. Basically, HS parameters are the harmony memory size (HMS), that is, the number of solution vectors lying on the harmony memory $(\mathrm{HM})$, the harmony memory consideration 
rate (HMCR), the pitch adjusting rate (PAR), the distance bandwidth (BW), and the number of improvisations (NI), which represents the total number of iterations. These HS parameters, with the exception of NI, were obtained from Oliva et al. [20]. HS is stopped when the NI maximum is reached.

Table 2. Parameters used for the PLBA method

\begin{tabular}{lc|}
\hline Parameter & Value \\
\hline Number of scout bees, $(n)$ & 26 \\
\hline Number of selected sites (patches), $(m)$ & 18 \\
\hline Number of elite sites (patches), $(e)$ & 9 \\
\hline Number of recruited bees for each site of e sites, (nep) & 25 \\
\hline $\begin{array}{l}\text { Number of bees recruited for every site of the remaining } \\
(m-e) \text { sites, ( } n s p)\end{array}$ & 21 \\
\hline Step size of Levy flights (local), $\left(Y_{1}\right.$ _init & \\
\hline Step size of Levy flights (initial), $\left(\gamma_{2}\right)$ & 0.01 \\
\hline Step size of Levy flights (global), $\left(Y_{3}\right)$ & 0.5 \\
\hline
\end{tabular}

Table 3. Parameters used for the HS method

\begin{tabular}{|lc|}
\hline Parameter & Value \\
\hline Harmony Memory Consideration Rate, (HMCR) & 0.75 \\
\hline Harmony Memory Size (HMS) & 100 \\
\hline Pitch Adjusting Rate (PAR) & 0.5 \\
\hline Bandwidth (bw) & 0.5 \\
\hline Number of Improvisations (NI) & 100 \\
\hline
\end{tabular}

\subsection{EXPERIMENTAL ENVIRONMENT}

Both PLBA and HS based multilevel thresholding were implemented in the Matlab Language under operation system Microsoft 10 Pro. HS used the platform of Intel (R) Core ${ }^{\mathrm{TM}}$ i7-2620M CPU @ $2.70 \mathrm{GHz} 2.70 \mathrm{GHz}$ and 4.00 GB RAM. On the other hand, the PLBA used the platform of Intel (R) Core ${ }^{\mathrm{TM}}$ i7-2640M CPU @ 2.80 $\mathrm{GHz} 2.80 \mathrm{GHz}$ and $8.00 \mathrm{~GB}$ RAM.

\section{RESULTS AND DISCUSSION}

\subsection{SOLUTION QUALITY}

The mean values of Otsu's objective functions and PLBA and HS optimal thresholds are shown in Table 4 and Table 5, respectively.

PLBA and HS algorithms yield different solution quality (thresholds). In Table 4, it can be observed that the PLBA algorithms provide higher objective values than HS for Otsu's criteria in relation to all numbers of thresholds. It is triggered by the balance of PLBA search through its exploitation and exploration.

An example of segmented images and corresponding thresholds on the histogram obtained by means of PLBA and HS algorithms at threshold levels 2, 3, 4 and 5 are shown in Fig 2. In these figures, it can be observed that a segmented image has high performance when $(C=5)$, compared with $(C=4),(C=3)$ and $(C=2)$.
The one-way ANOVA test is the most suitable statistical test for comparing two algorithms during performance evaluation. Table 6 presents the one-way ANOVA test results regarding the objective value obtained from Table 4.

Table 4. Objective value

\begin{tabular}{|c|c|c|c|}
\hline \multirow{2}{*}{ Test images } & \multirow{2}{*}{ c } & \multicolumn{2}{|c|}{ Objective value } \\
\hline & & HS & PLBA \\
\hline \multirow{4}{*}{ Slice 9} & 2 & 2758.6035 & 2763.7052 \\
\hline & 3 & 2860.9283 & 2868.5840 \\
\hline & 4 & 2917.8225 & 2931.5630 \\
\hline & 5 & 2954.8262 & 2972.7936 \\
\hline \multirow{4}{*}{ Slice 162} & 2 & 2622.7353 & 2626.3231 \\
\hline & 3 & 2732.7760 & 2741.0923 \\
\hline & 4 & 2771.1317 & 2783.9228 \\
\hline & 5 & 2789.8760 & 2803.7704 \\
\hline \multirow{4}{*}{ Slice 164} & 2 & 2623.0531 & 2627.7604 \\
\hline & 3 & 2716.4348 & 2725.4572 \\
\hline & 4 & 2756.4526 & 2766.9936 \\
\hline & 5 & 2774.8761 & 2788.3459 \\
\hline \multirow{4}{*}{ Slice 165} & 2 & 2565.0053 & 2570.0430 \\
\hline & 3 & 2666.8996 & 2673.9924 \\
\hline & 4 & 2711.1194 & 2724.5949 \\
\hline & 5 & 2734.9181 & 2748.9369 \\
\hline \multirow{4}{*}{ Slice 166} & 2 & 2565.7274 & 2569.4757 \\
\hline & 3 & 2667.6062 & 2676.2994 \\
\hline & 4 & 2709.1167 & 2722.3494 \\
\hline & 5 & 2730.9521 & 2742.9301 \\
\hline \multirow{4}{*}{ Slice 167} & 2 & 2420.4071 & 2423.1809 \\
\hline & 3 & 2509.1811 & 2517.1797 \\
\hline & 4 & 2549.3627 & 2561.3904 \\
\hline & 5 & 2569.7299 & 2580.8872 \\
\hline \multirow{4}{*}{ Slice 168} & 2 & 2584.4892 & 2588.6853 \\
\hline & 3 & 2677.9138 & 2687.0771 \\
\hline & 4 & 2724.5460 & 2736.6637 \\
\hline & 5 & 2741.9034 & 2757.2897 \\
\hline \multirow{4}{*}{ Slice 169} & 2 & 2608.3955 & 2614.3364 \\
\hline & 3 & 2720.6385 & 2729.8284 \\
\hline & 4 & 2764.5079 & 2776.8937 \\
\hline & 5 & 2785.0359 & 2800.5414 \\
\hline \multirow{4}{*}{ Slice 38} & 2 & 1836.3968 & 1838.5189 \\
\hline & 3 & 1916.8307 & 1922.6860 \\
\hline & 4 & 1947.7889 & 1955.8094 \\
\hline & 5 & 1965.1856 & 1974.0217 \\
\hline
\end{tabular}

The hypothesis made for the analysis of Table 6 is as follows: 
Null hypothesis, HO: There is no significant difference in the objective value between the two methods (the PLBA and HS).

Alternative hypothesis, H1: There is a significant difference in the objective value between the two methods (the PLBA and HS).

Table 5. Optimal threshold value

\begin{tabular}{|c|c|c|c|}
\hline \multirow{2}{*}{ Test images } & \multirow{2}{*}{ c } & \multicolumn{2}{|c|}{ Optimal threshold values } \\
\hline & & HS & PLBA \\
\hline \multirow{4}{*}{ Slice 9} & 2 & 48,121 & 43,123 \\
\hline & 3 & $43,96,147$ & $39,95,158$ \\
\hline & 4 & $43,86,130,193$ & $35,75,114,169$ \\
\hline & 5 & $19,49,106,141,203$ & $34,69,97,133,177$ \\
\hline \multirow{4}{*}{ Slice 162} & 2 & 44,128 & 43,123 \\
\hline & 3 & $44,99,166$ & $39,95,158$ \\
\hline & 4 & $33,75,114,168$ & $35,75,114,169$ \\
\hline & 5 & $39,77,104,130,175$ & $34,69,97,133,177$ \\
\hline \multirow{4}{*}{ Slice 164} & 2 & 45,128 & 42,120 \\
\hline & 3 & $32,90,146$ & $38,90,148$ \\
\hline & 4 & $33,76,118,167$ & $35,75,116,166$ \\
\hline & 5 & $30,62,92,130,170$ & $32,66,94,133,176$ \\
\hline \multirow{4}{*}{ Slice 165} & 2 & 46,122 & 44,121 \\
\hline & 3 & $45,97,149$ & $41,96,154$ \\
\hline & 4 & $44,96,132,164$ & $36,77,118,172$ \\
\hline & 5 & $32,63,88,127,181$ & $34,71,101,139,184$ \\
\hline \multirow{4}{*}{ Slice 166} & 2 & 47,128 & 46,125 \\
\hline & 3 & $41,98,156$ & $42,95,154$ \\
\hline & 4 & $36,86,118,171$ & $37,78,115,167$ \\
\hline & 5 & $34,76,102,144,205$ & $36,75,106,147,192$ \\
\hline \multirow{4}{*}{ Slice 167} & 2 & 43,124 & 45,122 \\
\hline & 3 & $44,92,162$ & $41,94,151$ \\
\hline & 4 & $4287,137,179$ & $38,82,122,175$ \\
\hline & 5 & $30,69,105,156,188$ & $36,74,102,138,184$ \\
\hline \multirow{4}{*}{ Slice 168} & 2 & 49,126 & 46,125 \\
\hline & 3 & $44,112,168$ & $42,95,154$ \\
\hline & 4 & $32,81,116,167$ & $37,78,115,167$ \\
\hline & 5 & $19,46,77,126,177$ & $36,75,106,147,192$ \\
\hline \multirow{4}{*}{ Slice 169} & 2 & 48,135 & 44,121 \\
\hline & 3 & $46,100,165$ & $41,96,154$ \\
\hline & 4 & $42,85,121,157$ & $36,77,118,172$ \\
\hline & 5 & $34,72,108,141,186$ & $34,71,101,139,184$ \\
\hline \multirow{4}{*}{ Slice 38} & 2 & 59,164 & 42,120 \\
\hline & 3 & $49,97,180$ & $38,90,148$ \\
\hline & 4 & $33,81,128,196$ & $35,75,116,166$ \\
\hline & 5 & $38,74,98,145,222$ & $32,66,94,133,176$ \\
\hline
\end{tabular}

Table 6. One-way ANOVA test of the PLBA and HS based on the objective value (Otsu)

\begin{tabular}{cccccccc|}
$\begin{array}{c}\text { Source of } \\
\text { Variation }\end{array}$ & SS & Df & MS & $\boldsymbol{F}$ & P-value & $\boldsymbol{F}$ crit \\
$\begin{array}{c}\text { Between } \\
\text { Groups }\end{array}$ & 1612.64 & 2 & 806.32 & 0.0107 & 0.9894 & 3.1296 \\
$\begin{array}{c}\text { Within } \\
\text { Groups }\end{array}$ & 5202052 & 69 & 75392.06 & & \\
& & & & & & \\
Total & 5203665 & 71 & & & \\
\end{tabular}

Table 7. Uniformity

\begin{tabular}{|c|c|c|c|}
\hline \multirow{2}{*}{ Test images } & \multirow{2}{*}{ c } & \multicolumn{2}{|c|}{ Uniformity } \\
\hline & & HS & PLBA \\
\hline \multirow{5}{*}{ Slice 9} & 2 & 0.9819 & 0.9820 \\
\hline & 3 & 0.9826 & 0.9827 \\
\hline & & & \\
\hline & 4 & 0.9842 & 0.9847 \\
\hline & 5 & 0.9841 & 0.9873 \\
\hline \multirow{5}{*}{ Slice 162} & 2 & 0.9862 & 0.9863 \\
\hline & 3 & 0.9898 & 0.9901 \\
\hline & & & \\
\hline & 4 & 0.9920 & 0.9921 \\
\hline & 5 & 0.9924 & 0.9932 \\
\hline \multirow{5}{*}{ Slice 164} & 2 & 0.9865 & 0.9868 \\
\hline & 3 & 0.9890 & 0.9893 \\
\hline & & & \\
\hline & 4 & 0.9908 & 0.9908 \\
\hline & 5 & 0.9916 & 0.9918 \\
\hline \multirow{4}{*}{ Slice 165} & 2 & 0.9855 & 0.9855 \\
\hline & 3 & 0.9876 & 0.9879 \\
\hline & 4 & 09875 & 0.9901 \\
\hline & 5 & 0.9908 & 0.9913 \\
\hline \multirow{4}{*}{ Slice 166} & 2 & 0.9856 & 0.9856 \\
\hline & 3 & 0.9883 & 0.9883 \\
\hline & 4 & 0.9896 & 0.9901 \\
\hline & 5 & 0.9902 & 0.9908 \\
\hline \multirow{5}{*}{ Slice 167} & 2 & 0.9874 & 0.9874 \\
\hline & 3 & 0.9892 & 0.9898 \\
\hline & & & \\
\hline & 4 & 0.9912 & 0.9918 \\
\hline & 5 & 0.9914 & 0.9928 \\
\hline
\end{tabular}




$\begin{array}{cccc} & 2 & 0.9860 & 0.9860 \\ \text { Slice } 168 & 3 & 0.9872 & 0.9881 \\ & 4 & 0.9898 & 0.9902 \\ & 5 & 0.9893 & 0.9910 \\ & 2 & 0.9844 & 0.9848 \\ & 3 & 0.9876 & 0.9879 \\ & 4 & 0.9886 & 0.9897 \\ & 5 & 0.9905 & 0.9908 \\ & 2 & 0.9895 & 0.9895 \\ & & 0.9918 & 0.9920 \\ & 3 & 0.9932 & 0.9935 \\ & 4 & 0.9941 & 0.9946\end{array}$

Table 8. One-way ANOVA test of the PLBA and HS based on uniformity

\begin{tabular}{cccccccc}
$\begin{array}{c}\text { Source of } \\
\text { Variation }\end{array}$ & SS & $\boldsymbol{d f}$ & $\boldsymbol{M S}$ & $\boldsymbol{F}$ & $\boldsymbol{P}$-value & $\boldsymbol{F}$ crit \\
$\begin{array}{c}\text { Between } \\
\text { Groups }\end{array}$ & $5.12 \mathrm{E}-06$ & 1 & $5.12 \mathrm{E}-06$ & 0.564127 & 0.45512 & 3.977779 \\
\hline $\begin{array}{c}\text { Within } \\
\text { Groups }\end{array}$ & 0.000635 & 71 & $9.08 \mathrm{E}-06$ & & \\
& & & & & & \\
Total & 0.00064 & 71 & & & \\
\end{tabular}

The $p$ values are greater than 0.05 (a significance level of $5 \%$ ) and the $\mathrm{F}$ value is less than F-critical, therefore the null hypothesis cannot be rejected. Hence, it is concluded that there is no significant difference in the objective value between the PLBA and HS.

\subsection{UNIFORMITY}

A uniformity measure of the PLBA yields the highest values of HS (refer to Table 7) in all of the test images and thresholds, with the exception of two thresholds in slices 165, 166, 167, 168 and 38. The PLBA algorithm has successfully demonstrated and yielded the best quality of segmented images.

Table 8 portrays the single-factor ANOVA test results regarding the uniformity obtained from Table 7.

The hypothesis made for the analysis of Table 8 is as follows:

Null hypothesis, H0: There is no significant difference in the uniformity between the two methods, i.e. the PLBA and HS.

Alternative hypothesis, H1: There is a significant difference in the uniformity between the two methods, i.e. the PLBA and HS.
The $p$ values are greater than 0.05 (a significance level of 5\%) and the F value is less than F-critical; therefore, the null hypothesis will not be rejected. Hence, this concludes that there is no significant difference in the uniformity between the PLBA and HS.

\subsection{STABILITY}

Based on Table 10, the PLBA algorithm shows a lower standard deviation value for all image thresholds. Thus, the PLBA is more stable compared to HS.

Table 9 presents the one-way ANOVA test results regarding uniformity obtained from Table 10.

The hypothesis made for the analysis of Table 9 is as follows:

Null hypothesis, Ho: There is no significant difference in the standard deviation between the two methods, i.e. the PLBA and HS.

Alternative hypothesis, H1: There is a significant difference in the standard deviation between the two methods, i.e. the PLBA and HS.

The $p$ values are less than 0.05 (a significance level of $5 \%$ ) and the $\mathrm{F}$ value is greater than F-critical, by virtue of which the null hypothesis is rejected. Hence, it is concluded that there is a significant difference in the standard deviation between the PLBA and HS.

Table 9. One-way ANOVA test of the PLBA and HS based on standard deviation

\begin{tabular}{cccccccc|}
$\begin{array}{c}\text { Source of } \\
\text { Variation }\end{array}$ & SS & $\boldsymbol{d f}$ & $\boldsymbol{M S}$ & $\boldsymbol{F}$ & $\boldsymbol{P}$-value & $\boldsymbol{F}$ crit \\
$\begin{array}{c}\text { Between } \\
\text { Groups }\end{array}$ & $5.12 \mathrm{E}-06$ & 1 & 543.7303 & 568.3898 & $2.53 \mathrm{E}-35$ & 3.977779 \\
\hline $\begin{array}{c}\text { Within } \\
\text { Groups }\end{array}$ & 0.000635 & 70 & 0.956615 & & \\
& & & & & & \\
Total & 0.00064 & 71 & & & \\
\end{tabular}

\subsection{STRUCTURAL SIMILARITY INDEX (SSIM)}

Table 11 shows that the SSIM of the PLBA is mostly higher than HS. Some SSIM of HS is higher than the PLBA, such as slices 166,168 and 38 for $c=3$, and slices 167 and 169 for $C=2$.

\subsection{PEAK SIGNAL-TO-NOISE RATIO (PSNR)}

The results of the PSNR value in all images (refer to Table 11) are directly proportional to the increasing threshold values even though $\mathrm{HS}$ has achieved a higher PSNR value for most images and thresholds. The PSNR value of the PLBA is the best value in $c=5$ for slices $9,162,164$ and 165 . Thus, well segmented images provide a better result when the level of thresholds is high. 


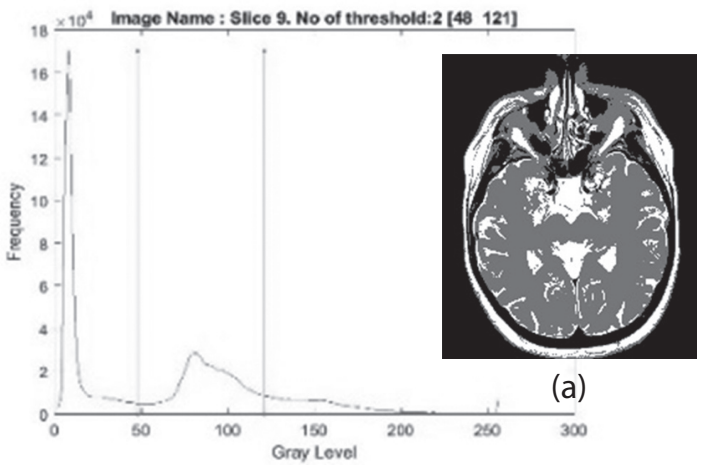

(a')

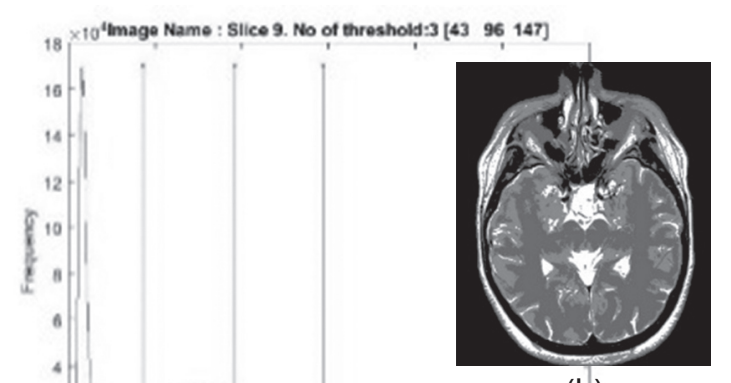

(b)

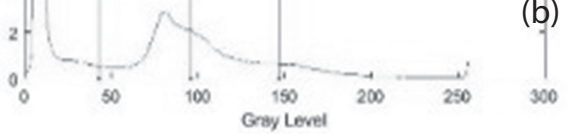

(b')

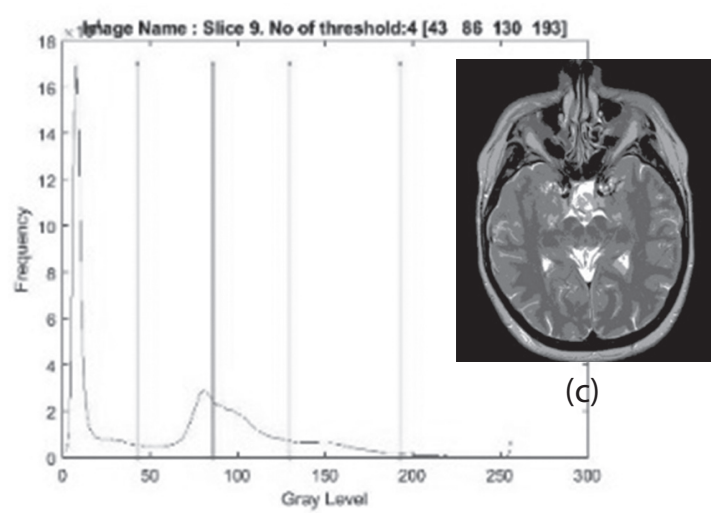

(c')

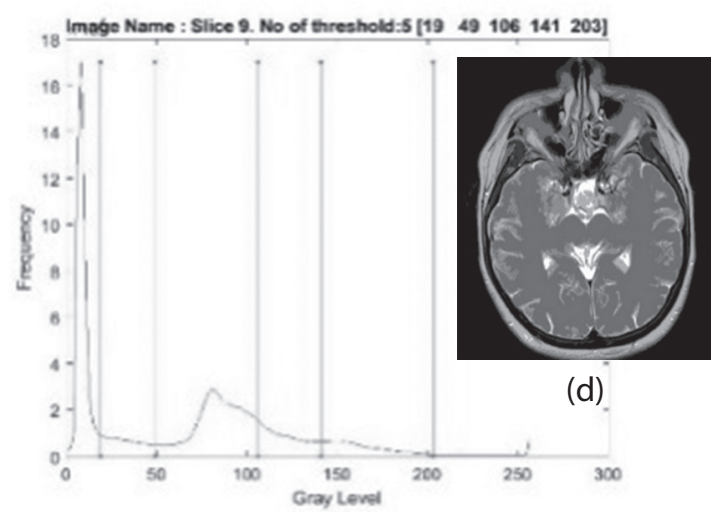

$\left(d^{\prime}\right)$

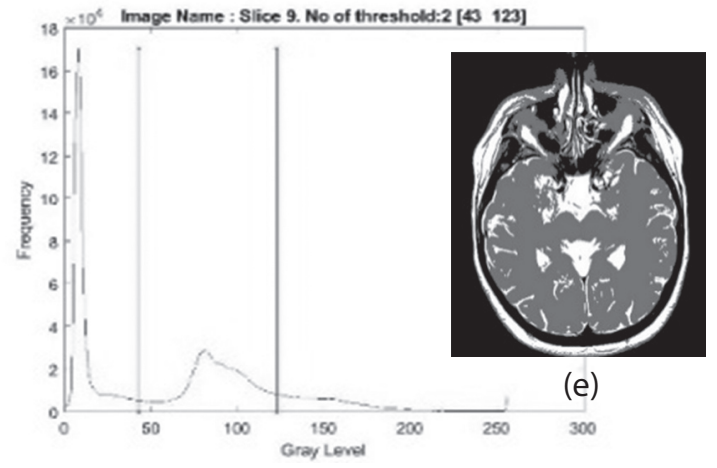

$\left(\mathrm{e}^{\prime}\right)$

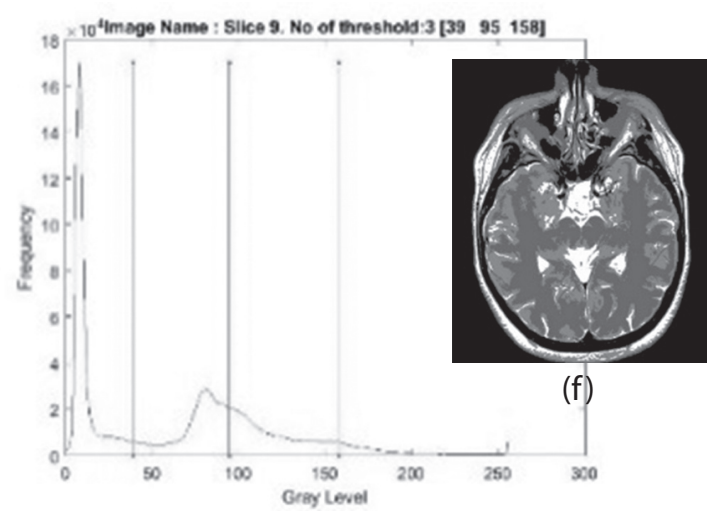

(f')

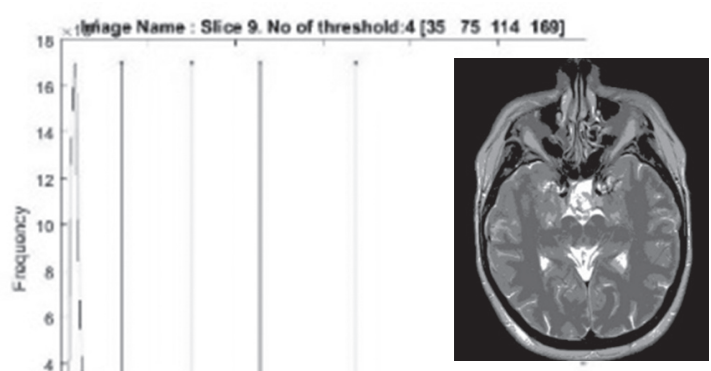

(g)

$\left(g^{\prime}\right)$

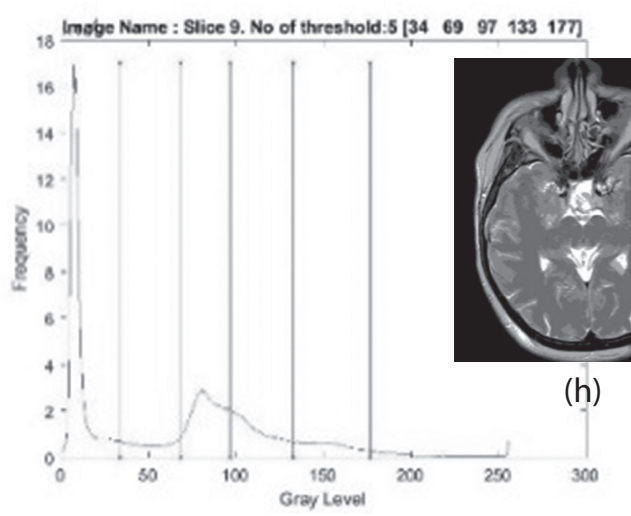

(h')

Fig. 2. Segmented images and histograms with the threshold of the Slice 9 image. (a)-(d) are the segmented images of HS for $c=2,3,4,5$, respectively. $\left(a^{\prime}\right)$-(d') give histograms with thresholds of HS for $c=2,3,4,5$, respectively. (e)-(h) show segmented images of the PLBA for $c=2,3,4,5$, respectively. $\left(e^{\prime}\right)$-( $\left(h^{\prime}\right)$ are histograms with thresholds of the PLBA for $\mathrm{c}=2,3,4,5$, respectively. 
Table 10. Standard deviation

\begin{tabular}{|c|c|c|c|}
\hline \multirow{2}{*}{$\begin{array}{c}\text { Test } \\
\text { images }\end{array}$} & \multirow{2}{*}{ c } & \multicolumn{2}{|c|}{ Standard deviation } \\
\hline & & HS & PLBA \\
\hline \multirow{4}{*}{ Slice 9} & 2 & $5.44 \mathrm{E}+00$ & $1.84 \mathrm{E}-12$ \\
\hline & 3 & $5.88 \mathrm{E}+00$ & 3.67E-12 \\
\hline & 4 & $5.59 \mathrm{E}+00$ & $1.38 \mathrm{E}-12$ \\
\hline & 5 & $6.38 \mathrm{E}+00$ & $1.38 \mathrm{E}-12$ \\
\hline \multirow{4}{*}{ Slice 162} & 2 & $4.09 E+00$ & $1.84 \mathrm{E}-12$ \\
\hline & 3 & $5.73 \mathrm{E}+00$ & $9.19 \mathrm{E}-13$ \\
\hline & 4 & $6.36 \mathrm{E}+00$ & $4.59 \mathrm{E}-13$ \\
\hline & 5 & $5.74 \mathrm{E}+00$ & $1.38 \mathrm{E}-12$ \\
\hline \multirow{4}{*}{ Slice 164} & 2 & $4.55 \mathrm{E}+00$ & $1.38 \mathrm{E}-12$ \\
\hline & 3 & $6.68 \mathrm{E}+00$ & $2.76 \mathrm{E}-12$ \\
\hline & 4 & $5.73 \mathrm{E}+00$ & $2.30 \mathrm{E}-12$ \\
\hline & 5 & $5.89 \mathrm{E}+00$ & $4.59 \mathrm{E}-13$ \\
\hline \multirow{4}{*}{ Slice 165} & 2 & $4.95 \mathrm{E}+00$ & $2.76 \mathrm{E}-12$ \\
\hline & 3 & $5.16 \mathrm{E}+00$ & $1.84 \mathrm{E}-12$ \\
\hline & 4 & $7.56 \mathrm{E}+00$ & $3.22 \mathrm{E}-12$ \\
\hline & 5 & $5.58 \mathrm{E}+00$ & $1.84 \mathrm{E}-12$ \\
\hline \multirow{4}{*}{ Slice 166} & 2 & $3.91 \mathrm{E}+00$ & $1.84 \mathrm{E}-12$ \\
\hline & 3 & $5.19 \mathrm{E}+00$ & $1.38 \mathrm{E}-12$ \\
\hline & 4 & $6.62 \mathrm{E}+00$ & $0.00 E+00$ \\
\hline & 5 & $5.80 \mathrm{E}+00$ & $2.30 \mathrm{E}-12$ \\
\hline \multirow{4}{*}{ Slice 167} & 2 & $2.27 \mathrm{E}+00$ & $0.00 \mathrm{E}+00$ \\
\hline & 3 & $5.22 \mathrm{E}+00$ & $1.38 \mathrm{E}-12$ \\
\hline & 4 & $5.70 \mathrm{E}+00$ & $2.76 \mathrm{E}-12$ \\
\hline & 5 & $4.72 \mathrm{E}+00$ & $2.30 \mathrm{E}-12$ \\
\hline \multirow{4}{*}{ Slice 168} & 2 & $3.79 E+00$ & $1.84 \mathrm{E}-12$ \\
\hline & 3 & $6.20 E+00$ & $0.00 E+00$ \\
\hline & 4 & $7.45 E+00$ & $9.19 \mathrm{E}-13$ \\
\hline & 5 & $7.80 \mathrm{E}+00$ & $9.19 \mathrm{E}-13$ \\
\hline \multirow{4}{*}{ Slice 169} & 2 & $7.26 \mathrm{E}+00$ & $3.22 \mathrm{E}-12$ \\
\hline & 3 & $5.88 \mathrm{E}+00$ & $1.38 \mathrm{E}-12$ \\
\hline & 4 & $8.36 \mathrm{E}+00$ & $1.84 \mathrm{E}-12$ \\
\hline & 5 & $5.79 \mathrm{E}+00$ & $0.00 \mathrm{E}+00$ \\
\hline \multirow{4}{*}{ Slice 38} & 2 & $2.19 E+00$ & $2.30 \mathrm{E}-12$ \\
\hline & 3 & $4.60 \mathrm{E}+00$ & $9.19 \mathrm{E}-13$ \\
\hline & 4 & $3.91 \mathrm{E}+00$ & $2.30 \mathrm{E}-12$ \\
\hline & 5 & $3.89 \mathrm{E}+00$ & $2.30 \mathrm{E}-12$ \\
\hline
\end{tabular}

\section{CONCLUSION}

In this paper, the PLBA algorithm based multilevel thresholding using Otsu's criterion is discussed. T2 weighted brain MR axial plane images are applied as test images. It is observed that the PLBA is higher in terms of the fitness value (Otsu) and low standard deviation for all test images. The uniformity measure of PLBA based multilevel thresholding is mostly higher than $\mathrm{HS}$ and it represents the quality of the segmentation algorithm. The segmented image
Table 11. SSIM and PSNR

\begin{tabular}{|c|c|c|c|c|c|}
\hline \multirow{2}{*}{$\begin{array}{c}\text { Test } \\
\text { images }\end{array}$} & \multirow{2}{*}{ c } & \multicolumn{2}{|c|}{ SSIM } & \multicolumn{2}{|c|}{ PSNR } \\
\hline & & HS & PLBA & HS & PLBA \\
\hline \multirow{4}{*}{ Slice 9} & 2 & 0.9965 & 0.9966 & 15.4965 & 16.0045 \\
\hline & 3 & 0.9963 & 0.9966 & 19.2900 & 20.0090 \\
\hline & 4 & 0.9966 & 0.9967 & 25.1511 & 24.6520 \\
\hline & 5 & 0.9973 & 0.9971 & 26.8892 & 26.4528 \\
\hline \multirow{4}{*}{ Slice 162} & 2 & 0.9950 & 0.9952 & 18.4858 & 18.0336 \\
\hline & 3 & 0.9956 & 0.9959 & 22.6296 & 22.0558 \\
\hline & 4 & 0.9960 & 0.9960 & 23.5219 & 23.5852 \\
\hline & 5 & 0.9964 & 0.9964 & 24.2061 & 24.5045 \\
\hline \multirow{4}{*}{ Slice 164} & 2 & 0.9938 & 0.9942 & 18.0325 & 17.4480 \\
\hline & 3 & 0.9951 & 0.9952 & 20.1306 & 20.2950 \\
\hline & 4 & 0.9955 & 0.9956 & 22.7705 & 22.6308 \\
\hline & 5 & 0.9953 & 0.9954 & 23.4549 & 24.2083 \\
\hline \multirow{4}{*}{ Slice 165} & 2 & 0.9936 & 0.9940 & 17.4614 & 17.3748 \\
\hline & 3 & 0.9945 & 0.9948 & 20.7057 & 21.3318 \\
\hline & 4 & 0.9950 & 0.9951 & 22.7413 & 24.0679 \\
\hline & 5 & 0.9952 & 0.9953 & 25.4724 & 25.7841 \\
\hline \multirow{4}{*}{ Slice 166} & 2 & 0.9937 & 0.9937 & 18.2731 & 17.9921 \\
\hline & 3 & 0.9946 & 0.9944 & 21.7510 & 21.5713 \\
\hline & 4 & 0.9949 & 0.9949 & 23.4844 & 23.2063 \\
\hline & 5 & 0.9951 & 0.9951 & 26.6242 & 26.1298 \\
\hline \multirow{4}{*}{ Slice 167} & 2 & 0.9954 & 0.9952 & 18.1550 & 17.9531 \\
\hline & 3 & 0.9958 & 0.9961 & 22.6259 & 21.5298 \\
\hline & 4 & 0.9963 & 0.9964 & 24.9767 & 24.8232 \\
\hline & 5 & 0.9960 & 0.9964 & 26.1623 & 26.0267 \\
\hline \multirow{4}{*}{ Slice 168} & 2 & 0.9935 & 0.9935 & 17.8610 & 17.7754 \\
\hline & 3 & 0.9947 & 0.9945 & 22.4194 & 21.1367 \\
\hline & 4 & 0.9948 & 0.9950 & 23.1925 & 23.0741 \\
\hline & 5 & 0.9947 & 0.9952 & 24.5909 & 24.4890 \\
\hline \multirow{4}{*}{ Slice 169} & 2 & 0.9939 & 0.9938 & 18.6405 & 17.6448 \\
\hline & 3 & 0.9948 & 0.9948 & 22.2996 & 21.4387 \\
\hline & 4 & 0.9951 & 0.9952 & 22.0291 & 23.7089 \\
\hline & 5 & 0.9953 & 0.9954 & 25.2203 & 24.9809 \\
\hline \multirow{4}{*}{ Slice 38} & 2 & 0.9947 & 0.9946 & 20.9713 & 20.9083 \\
\hline & 3 & 0.9942 & 0.9940 & 22.2872 & 22.4437 \\
\hline & 4 & 0.9945 & 0.9947 & 23.3119 & 23.1477 \\
\hline & 5 & 0.9950 & 0.9952 & 23.4757 & 23.6046 \\
\hline
\end{tabular}

yields more information of the image when the number of threshold levels increases. The statistical performance of the PLBA and HS is evaluated by using one-way ANO$V A$. The test showed that there is a significant difference in standard deviation for both algorithms even though there exists no significant difference of the objective value and uniformity between the PLBA and HS. This proves that the PLBA is more stable than HS. A higher threshold level implies the effectiveness of brain MRI images to differentiate between normal and abnormal tissues. 


\section{ACKNOWLEDGMENT}

We would like to thank the Ministry of Higher Education and the National University Malaysia for providing the facilities, funding (AP-2017-005/2), and a huge appreciation for Dr. Wasim Abdulqawi Hussein for substantial assistance and providing the PLBA source code. We have also obtained ethical approval FF-2015-381 entitled Development of Automatic System Diagnosis for Cysts/Necrosis/Solid on MRI Brain Images for the period from 12 November 2015 to 11 November 2018.

\section{REFERENCES:}

[1] National Cancer Registry, National Cancer Institute, Ministry of Health Malaysia (2018). Malaysian Study on Cancer Survival (MySCan).

[2] F. Fuad, "Kanser pembunuh ketiga tertinggi di Malaysia", in Berita Harian, Berita Harian: Malaysia, 2017.

[3] V. Lights, "Brain Tumor", 2017. Available online (https://www.healthline.com/health/brain-tumor)

[4] R.N. Dave, "Characterization and detection of noise in clustering", Pattern Recognition Letters, Vol. 12, No. 11, 1991, pp. 657-664.

[5] M. Joliot, B.M. Mazoyer, "Three-dimensional segmentation and interpolation of magnetic resonance brain images", IEEE Transactions on Medical Imaging, Vol. 12, No. 2, 1993, pp. 269-277.

[6] R. Valdés-Cristerna, V. Medina-Bañuelos, O. YáñezSuárez, "Coupling of radial-basis network and active contour model for multispectral brain MRI segmentation", IEEE Transactions on Biomedical Engineering, Vol. 51, No. 3, 2004, pp. 459-470.

[7] N. Dhanachandra, Y.J. Chanu, "A survey on image segmentation methods using clustering techniques", European Journal of Engineering Research and Science, Vol. 2, No. 1, 2017, pp. 15-20.

[8] J.C. Bezdek, Pattern Recognition with Fuzzy Object Function Algorithms, Springer US, 1981.

[9] N. Otsu, "A threshold selection method from graylevel histograms", IEEE Transactions on Systems, Man, and Cybernetics, Vol. 9, No. 1, 1979, pp. 62-66.

[10] J. Kittler, J. Illingworth, "Minimum error thresholding", Pattern Recognition, Vol. 19, No. 1, 1986, pp. 41-47.

[11] D.-M. Tsai, "A fast thresholding selection procedure for multimodal and unimodal histograms", Pattern Recognition Letters, Vol. 16, No. 6, 1995, pp. 653-666.
[12] M. Maitra, A. Chatterjee, "A novel technique for multilevel optimal magnetic resonance brain image thresholding using bacterial foraging", Measurement, Vol. 41, No. 10, 2008, pp. 1124-1134.

[13] P.-Y. Yin, "A fast scheme for optimal thresholding using genetic algorithms", Signal Processing, Vol. 72, No. 2, 1999, pp. 85-95.

[14] P. Sathya, R. Kayalvizhi, "Optimal segmentation of brain MRI based on adaptive bacterial foraging algorithm", Neurocomputing, Vol. 74, No. 14-15, 2011, pp. 2299-2313.

[15] M. Chithradevi, C. Alagurani, "Harmony Search Optimization Algorithm Based Multilevel Thresholding for MRI Brain Images" International Journal of Engineering Trends and Applications (IJETA), Vol. 5, No. 2, 2018, pp. 39-45.

[16] W.A. Hussein, S. Sahran, S.N.H.S. Abdullah, "A fast scheme for multilevel thresholding based on a modified bees algorithm", Knowledge-Based Systems, Vol. 101, No. C, 2016, pp. 114-134.

[17] R.C. Gonzalez, R.E. Woods, S.L. Eddins, Digital image processing using MATLAB, 2004, Pearson-Prentice-Hall Upper Saddle River, New Jersey.

[18] Z.W. Geem, J.H. Kim, G.V. Loganathan, "A new heuristic optimization algorithm: harmony search", Simulation, Vol. 76, No. 2, 2001, pp. 60-68.

[19] Z.W. Geem, K.S. Lee, Y. Park, "Application of harmony search to vehicle routing", American Journal of Applied Sciences, Vol. 2, No. 12, 2005, pp. 15521557.

[20] D. Oliva, E. Cuevas, G. Pajares, D. Zaldivar, M. PerezCisneros, "Multilevel thresholding segmentation based on harmony search optimization", Journal of Applied Mathematics, Vol. 2013, 2013.

[21] I. Ahmad, M. G. Mohammad, A. A. Salman, S. A. Hamdan, "Broadcast scheduling in packet radio networks using Harmony Search algorithm", Expert Systems with Applications, Vol. 39, No. 1, 2012, pp. 1526-1535.

[22] P.K. Sahoo, S. Soltani, A.K. Wong, "A survey of thresholding techniques", Computer Vision, Graphics and Image Processing, Vol. 41, No. 2, 1988, pp. 233-260. 